change requires time to recover after the first causenamely, the pressure of bone, has been removed.

Of course the longer trephining is delayed the less chance is there of perfect recovery, and the greater the amount of change in the brain and medulla the greater is the improbability of recovery; yet $I$ think that the chances of improvement are so great that I should be inclined to recommend trephining in every similar case, no matter how far distant from the occurrence of the accident, provided of course that the surgeon found no reason from other conditions of the patient to veto the operation.

The case I have described I think may fairly be considered as successful and encouraging, especially as the operation and its result have enabled the patient to return to his work and again to earn his living.

I ought, perhaps, to mention that from time to time since the operation I have given the patient belladonna, in doses of one grain of extract mixed with one grain of the powdered leaf, three or four times a day. Occasionally I have varied this with a mixture of bromide and iodide of potassium, because belladonna loses its efficacy if taken for a long time without intermission. I have constantly given him codliver oil, omitting it only for short intervals, when it appeared to make him sick.

Upper George-street, $\mathrm{w}$.

\section{ON A CASE OF SUBPERIOSTEAL EXCISION OF THE HEAD AND PART OF THE SHAFT OF THE HUMERUS.}

\section{BY RODERICK MACLAREN, M.D.,} SURGEON TO THE CARLISLE DISPENSARY.

THe case that I have to relate is that of Joseph S-, aged six, admitted to the Carlisle Dispensary, November 2nd, 1871, as an out-patient. The history of his ailment before admission was not at all clear, as he had been under the care of various relatives during the previous two years; his mother having died before that from excision of the knee, the family was consequently disjointed. The statements made in reference to the origin of his illness were, that about twelve months ago he fell and broke his right collar-bone, and a few weeks afterwards again encountered an accident and "put his right shoulder out"; that he has never been right about that shoulder since; several abscesses have formed, and been opened or burst spontaneously, and that his general health has at times been very bad.

On admission (having newly returned from the country), he was a rosy-faced, well-nourished boy. In the neighbourhood of the right shoulder were five openings of sinuses. Two of these were over the second rib, another was at the axillary fold of the pectoral muscle, a fourth in the axilla a little below the middle of its thoracic wall, and the fifth was on the front of the arm three inches from the shoulderjoint. The first and second were openings of a common sinus, as were also the third and fourth. They ran in the direction and to the near neighbourhood of the shoulderjoint, and met internally. In the fifth sinus the probe passed directly backwards. No bare bone could be felt. There was hardly any voluntary mobility of the arm, and forcible motion caused great pain. Before recommending operation, I resolved to try the effect of mechanical rest and the injection of the sinuses with iodine. No good result followed this treatment, and a month after he was admitted as a patient another abscess formed, and was opened close to the insertion of the deltoid. When this was probed there was found at the bottom a small bony cavity with bare walls.

As the boy's health was beginning again to suffer, I advised his friends to consent to excision, and on December 13th the following operation was performed. A straight incision somewhat external to the bicipital groove was made from the head of the bone to half an inch below the sinus furthest down the arm. The periosteum of the shaft and the perichondrium of the epiphysis were divided with the scalpel, and then with a periosteum elevator I endeavoured to detach each. From the bone this was a matter of no great difficulty, but from the epiphysis the reverse was the case, it being impossible to distinguish with the instrument between cartilage and the other tissues with sufficient exactness to separate them properly. The whole of the periosteum was left behind except a small bit that $I$ could cover with the point of my finger, but I do not think that much of the perichondrium remained in its place. I had planned to divide the bone a little below the lowest sinus, and, as it seemed quite healthy there, I did so. When the piece was removed, it was seen that the saw had passed through a cavity filled with a substance resembling marrow. Some of my colleagues thought at the time that it was an abscess in the bone, while $I$ held the opinion that it was the medullary cavity. A needle was passed down it for an inch without touching the bottom, and I determined to let it alone whatever it was, having the hope that, even if it turned out to be an abscess, the opening of it might result in healing. Subsequent microscopic examination showed the contents to consist of shrivelled pus-cells. The wound was washed out with carbolic-acid lotion and dressed with Lister's dressing. There was little hope that it could be made or kept antiseptic on account of the sinuses and the free open suppuration that had so long existed, but it seemed right to make the attempt; it did actually fail, the original conditions being such as almost certainly to preclude success. A pad was placed in the axilla, and the arm was bandaged to the side. I did not use any splint, nor did I throughout the case attempt extension, my reason being that I did not know to what ertent reproduction would occur, and an arm shorter than usual, but with a substantial joint, would be more useful than one of the normal length, with a loose and flaceid joint.

Twelve days after the operation the boy was able to come to the dispensary to get the wound dressed. I need not enter into the various fluctuations in the progress of the case; it will suffice to say that in six months the deep wounds were closed, and only superficial ulcers over the sinuses and the middle of the incision left. In sir weeks more these had also healed. The condition of the boy's arm ten months after the operation was as follows:-It remained one inch shorter than the other; the head of the bone had not been redeveloped; the deltoid was atrophied, but not so much so as it was a few months ago. The amount of motion may be thus described: the elbow could be abducted three inches from the side; the arm could be extended so as to bring the wrist (the limb being kept straight) to the level of the xiphoid cartilage ; the arm could

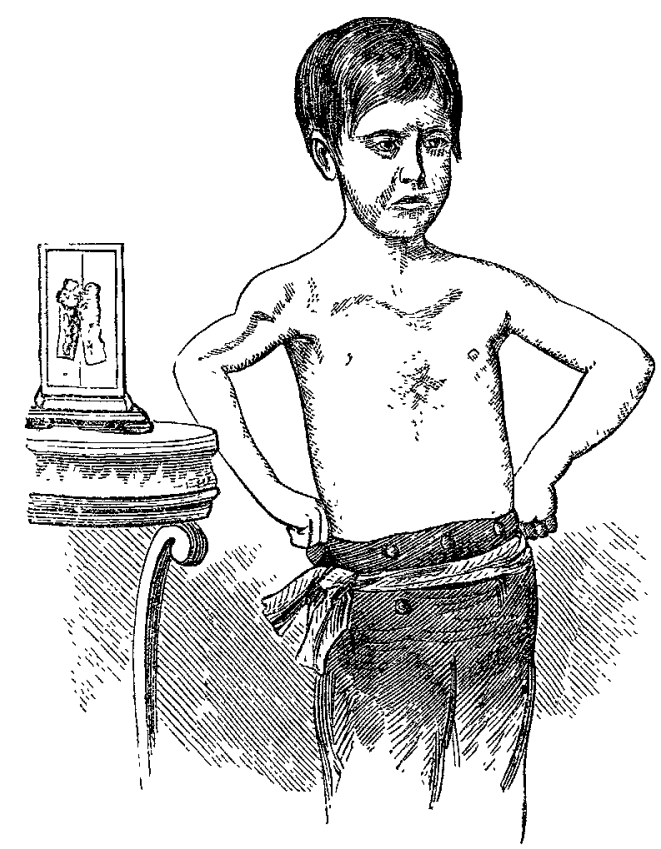

From a photograph.-In the engraving the arm operated on is represented as rather shorter from shoulder to elbow than it is in the photograph; the cicatrix on the arm is too long; and the cicatrix on the breast is not so well marked as might be desired.

be carried back to the normal extent, and rotated through one-eighth of a circle; his hand he could readily raise to his face, and by a sort of climbing movement of the fingers 
place the palm on the top of the head. He fed and dressed himself.

The specimen of bone removed measured three inches and a half in length. It has on its surface three openings, two of which lead into cavities in the cancellated texture; the third passes through the upper part of the diaphysis, and through the epiphysis into the joint. There are several shallow carious pits on various parts of the surface. The bone is slightly bent, and at its middle is a mark which looks like the result of a fracture. Section shows numerous carities in the bone. The glenoid cavity, I should have stated before, was healthy.

In this case, when expectant treatment failed (and how thoroughly hopeless it was the preparation removed shows), the operation performed was the only alternative to amputation; for had so long a piece of the bone been removed, in the ordinary manner covered with its periosteum, from a child of six years of age, one could not have hoped for anything better than a useless dangling limb, and it was only the prospect of the bone being reproduced that induced me to operate.

The boy is now at a distance from Carlisle, and I have not had the opportunity of seeing him lately, but his relations tell me that the arm is still gaining in strength and freedom of movement. For all actions below the level of the shoulder it is nearly as powerful as the other arm; he can, for example, wheel a barrow with half a hundredweight of coal in it. I have to-day (May 26th) received from the boy's friends the following measurements:-Left arm, shoulder to elbow, $8 \frac{8}{4}$ in.; right arm, shoulder to elbow, $7 \frac{1}{2}$ in. These show, during the last seven months, a slight increase in length of both arms, but a gain of a quarter of an inch more on the unoperated than the operated limb.

If it again fell to my lot to have the treatment of a similar case, in two respects $I$ should act differently. In the first place, instead of attempting to remove the perichondrium, I would endeavour to leave a thin shell of cartilage wherever it was healthy. It would be much easier to do this, and much more likely to give a successful result. In the second place, I should by galvanism at tempt to keep alive the contractile power of the deltoid. No doubt the paralysis and wasting of this muscle, which almost always occurs after excision of the shoulder, is due to injury of the circumflex nerve; and if the muscle were brought into regular action by the use of the current when the nerve recovered, it would find the muscle able and ready to respond to its dictates.

This case was well adapted for testing the value of the subperiosteal method of excision. While, on the one hand, the amount of diseased bone to be removed was very great, and involved the separation from the bone of many of the muscles which perform the most important movements of the arm, on the other hand, the origin of the disease was distinctly the result of injury, the boy's general health was fair, and he was of an age when reproduction is active. For M. Ollier has pointed out that, in reproducing bone, the periosteum is doing nothing else than continuing its normal functions, it being the main agent of the growth and nutrition of this structure. This explains why in young subjects bony reproduction is so much more active than in old, the membrane being most vigorous while the bone is still growing. It also explains why some bones and some portions of bones are better regenerated than others, the growth being most active where the membrane is thickest.

The result has been such as to make one think well of the utility of the procedure; for of three inches and a half of bone removed (nearly half the humerus), two inches and a half were reformed. The arm is a very useful one, and many motions are restored, although the insertions of the producing muscles were divided - as, for example, those producing rotation.

Carlisle.

Royal Medical Benevolent Fund Society of IBELAND.-The thirty-first annual meeting was held on the 2nd June, Dr. Frederick Kirkpatrick (president) presiding. We are happy to state that this deserving society is in a most prosperous condition, the total receipts from donations, subscriptions, and bequests during the year amounting to £2254. The applicants for relief numbered eightysix, of whom seventeen were first applications, sixty-eight were from widows, and nine from medical practitioners.

\section{CEREBRAL RHEUMATISM.}

BY CORNELIUS BLACK, M.D. LoND., M.R.C.P., CORRBSPONDING WRLLOW OF THE IMPERTAL SOCIBTY OP PHYSICIANS OF VIENAA, CORRESPONDING MEMBER OF THE IMPBRIAL SOCIETY OF MEDICIN B OF LXONS, BTC.

IN acute articular rheumatism, and especially when rheumatic pericarditis or endocarditis, or both coexist, cerebral rheumatism is not an unfrequent accompaniment in the more urgent period of the articular disease. It is manifested by a busy, talkative delirium, occasional disposition to leave the bed, flushed face not unfrequently bathed in perspiration, restless, sparkling eyes, and slight contraction of the pupils. With this form of cerebral rheumatism every medical practitioner is familiar. There is, however, another form of cerebral rheumatism which is probably of not less frequent occurrence, but which is not generally recognised, or if recognised, it has not, so far as I know, been described either in medical books or in the medical periodicals.

A case of this latter kind has very recently been under $\mathbf{m y}$ care. The subject of it was a gentleman of middle life, of nervosanguine temperament, and of regular and temperate habits. From the age of fourteen to that of thirty-nine be passed through five attacks of acute articular rbeumatism. In none of these attacks did the heart suffer. As in such subjects, so in him, migratory rheumatism was of frequent occurrence. In one such attack he suffered for some days from rheumatic pains in the ankles, loins, shoulders, arms, neck, and scalp, with no more marked disturbance of the health than a little indigestion. The urine was natural in quantity, deepish-yellow in colour, had a specific gravity of 1028, a strongly acid reaction, and deposited on cooling a large quantity of cayenne-pepper-coloured crystals of uric acid. About nine o'clock one morning, af ter expressing his freedom from rheumatic pains, he somewhat suddenly began to feel giddy and to complain of a sensation of weight and heaviness in the head generally and of a tendency to fall in whatever direction the head might be inclined. Occasionally the sensation of a whiz passed with electric rapidity through the brain from back to front. At other times a vertiginous sensation was referred to the vertex, when the gait became somewhat unsteady. His intellect was unclouded, be could indite letters as before, but if he had to think, his ideas soon became a little confused.

There was no increased heat of the head or of the skin generally, no nausea or vomiting, no injection of the sclerotica, no contraction or alteration of the pupils, no twitching of the muscles of the face or of those of any of the extremities. In one or two previous attacks slight twitchings of the muscles of the cheeks and of the brow had occurred, a common result of migratory rheumatism. The breathing was easy, regular, and the number of respirations seventeen per minute. The tongue was quite moist, but slightly furred, there was no thirst, the appetite for food was not sensibly altered, the bowels were regular. The heart and kidneys were healthy. The pulse, usually 70 in health, presented the peculiarity of now numbering only fifty-four per minute, a common result of depressed functional energy of the brain. It was regular, equal, soft, and rose beneath the finger with a slow, steady, measured beat. The quantity of urine voided within the first twelve hours was thirty-five ounces, but afterwards this proportionate ratio decreased, so that the urine did not exceed fifty ounces altogether for the first twenty-four hours. It was of a deep yellow colour, of acid reaction, specific gravity 1026, and was quite free from deposit after it had stood two days.

Perfect quietude was enjoined. Two pills containing two grains of calomel and eight of the compound extract of colocynth were administered, and their action was favoured by an effervescing draught containing tartrate of soda. Five liquid evacuations were produced. The general heaviness and giddiness of the head now merged into a sensation of diminished pressure over the left brow and an aching soreness confined to the left temple. This feeling shortly afterwards passed in succession to the muscles of the back of the neck, producing stiffness and more or less pain on motion-to the shoulders, wrists, back, thighs, and ankles, manifesting in each locality its usual character of rheumatism. With this transfer from the head the pulse rose 